Marko Konjović

Central European University,

UDC 17.022.1:[159.9:17

Department of Philosophy

177.6:17.022.1

University of Belgrade,

Institute for Philosophy and Social Theory

marko.konjovic@instifdt.bg.ac.rs

\title{
REASONS OF LOVE AND MORAL THINKING
}

\begin{abstract}
There are two widely-held intuitions about morality. One is the claim that all persons have equal moral worth; the other is that sometimes we are morally allowed or even required to give preference to those individuals whom we love. How can we justify our reasons of love in the face of moral egalitarianism? As of recently, there are three mutually competing accounts of why it could be said that we have reasons of love: (i) the projects view, (ii) the relationship view, and (iii) the individuals view. In this paper, I first examine these three views and find fault with each of them as they stand. I then proceed to propose a complex, yet a more compelling, account of reasons of love that builds on the individuals view.
\end{abstract}

Key Words: reasons of love, moral equality, moral thinking, partiality, impartiality

\section{Introduction}

Daily life is infused with making moral decisions. How should we reach them? Consider the following case:

Drowning Mother: You are out on a nice and relaxing Sunday-afternoon stroll alongside the Danube river when you hear a commotion ahead: a splash of water and calls of distress. Running forward, you see two individuals who have fallen into the murky waters. There happens to be one life jacket on the sidewalk, which you grab while running towards the river's bank. Because the river is moving quickly, you will only be able to throw the life jacket to one of the individuals who has fallen in and save her; the other individual, sadly, will be carried away by the river. As you reach the river's bank, you realize, with great shock, that one of the individuals in the river is your beloved mother. Without another thought, you throw the life jacket to your mother and pull her to safety as the other individual - a stranger to you - floats away to her death. ${ }^{1}$

1 This example is a stylized and slightly altered version of the Drowning Wife case put forward initially by Charles Fried and made extremely popular by Bernard Williams (1981: 1-19). 
Although you - and most other people - might feel as though you acted rightly, you might nevertheless, upon reflection, worry whether you actually did the right thing. What is your justification for saving your mother rather than the stranger? Call the reasons for being partial towards your mother (your friend, your romantic partner, or your child) reasons of love. ${ }^{2}$ Love, on any account, demands that we give special consideration to those whom we love; that is, love asks us to give more weight, at least in some circumstances, to the well-being of our loved ones. This is because love involves seeing the beloved in a particular way and having a variety of beliefs about her, including, most notably, beliefs about her specialness. ${ }^{3}$ Plausibly, partiality is not only morally permitted, but it is also sometimes morally required, at least in certain contexts. ${ }^{4}$ (I say a bit more about this in the concluding section.) What is a matter of dispute, however, is what exactly justifies reasons of love.

The question arises, to a large extent, because a cornerstone of (Western) morality is the moral equality of persons thesis: everyone ought to be treated with "equal concern and respect" (to borrow Ronald Dworkin's (1977) eloquent phrase). The moral equality of persons thesis is not only deeply entrenched into our thinking but it is also germane in the fight against nepotism, sexism and misogyny, homophobia, transphobia, racism, xenophobia, ageism, and ableism (to give quite a few examples). How can we then justify that we are morally permitted or even required to give preference to those whom we love, at least in certain contexts?

The main goal of this paper is to offer the contours of a solution to this puzzle. The justification of reasons of love that I suggest stems from a dissatisfaction with three prominent answers which have been advanced in recent philosophical literature; Simon Keller (2013) helpfully classifies them as: (i) the projects view, (ii) the relationship view, and (iii) the individuals view. In Section 2, I examine these three views and find fault with each of them as they are articulated. I then proceed to offer, in Section 3, an account of reasons of love that builds anew on the individuals view. This story takes inspiration from one of Keller's suggestions regarding the role of relationships in accounting for reasons of love; it gives relationships, however, a different flavor. Moreover, the version of the individuals view I propose goes beyond Keller's inasmuch as it incorporates one somewhat neglected, yet important,

2 Samuel Scheffler (2006) refers to what I call "reasons of love" as "relationship-dependent reasons" while Diane Jeske (2008) calls them "reasons of intimacy." Simon Keller (2013) calls such reasons "reasons of partiality." These differences are, so far as I can tell, only terminological.

3 It is worth noting that I am speaking here about love for concrete persons (so, not about love for co-nationals, for example) and in general (so, regardless of any particular kind of love, such as romantic, friendly, or filial).

4 Nowadays, no one upholds the highly implausible idea that morality requires us to always be impartial, so far as I am aware. Moreover, such extreme impartialism is, in all likelihood, psychologically impossible. 
theme of the projects view: the idea of a life worth living. In the concluding segment, Section 4, I briefly consider the issue of when partiality is justified; I suggest that there could be a principled way to distinguish between cases in which reasons of love rightfully reign and in which reasons of love ought to be banished.

\section{Three Love Stories}

The justification of reasons of love, on one general and quite popular strategy, need not appeal to any additional moral facts beyond the existence of a loving relationship. There are three such non-reductionist stories behind reasons of love: the projects view, the relationship view, and the individuals view. In this section I discuss in more detail these three proposals and present some of the more serious problems for each. Though the issues each view faces need not be decisive, they do motivate the search for an alternative justification.

Before I proceed, it is important to stress an important commitment which non-reductionists uphold. Namely, they develop their approach as a reaction to the standard reductionist justification of reasons of love: they complain that reductionists fail to offer a justification that is in line with the phenomenology of partiality since they focus on impartial moral principles. That a justification of reasons of love is in accordance with how we experience partiality means that our justification ought to correspond to our motivation (Keller 2013: 25-27). I take this to be a compelling point; however, as I argue in Section 3, there is a plausible account of reasons of love that does not separate our motivation from our justification but which is explicable in terms of impartial moral facts.

\section{The Projects View}

The projects view is most prominently defended by Bernard Williams (1981), to whom I owe a great deal for the Drowning Mother example. According to Williams, reasons of love are to be found in facts about me. That is, they refer to the reasons generated by our projects. The argument is, in a nutshell, that insofar as we have reasons to be partial to our own projects, we also have reasons to be partial to our loved ones. To assess the plausibility of the projects view, we first need a clearer idea of what a project is. Williams writes:

A man may have, for a lot of his life or even just for some part of it, a ground project or set of projects which are closely related to his existence and which to a significant degree give a meaning to his life (1981: 12). 
Ground projects, or projects for short, on a plausible interpretation, are a set of vital concerns, interests, or goals. These might be outcome oriented (such as finishing a $\mathrm{PhD}$ ) or ongoing (such as parenting). Ground projects are not, according to Williams, mere desires or preferences because they (i) have a greater influence on our self-understanding, and (ii) they are rooted in a history of commitment. ${ }^{5}$ These two differences also explain why we have reasons to prefer our own projects to someone else's: should we abandon our projects, we would lose an important part of ourselves. Morality, however, must not make such a high demand.

The main claim of the projects view is that loving relationships are like our ground projects. Indeed, we typically take our beloved to be a more or less central component of our life and identity: loving someone can come to play an important role in the self-conception of each lover. ${ }^{6}$ This applies regardless of whether we think about romantic lovers, friends, or family members. Indeed, a future in which my romantic partner, friend, or mother, to take a few examples, is absent would be very different than my present. So, reasons of love are justified insofar as loving another person takes on the role of a ground project.

The projects view, one might initially object, faces the Focus Objection. There seems to be something disturbing in thinking that I am justified in saving my drowning mother because she is crucial for my ground project of being a good son. That is, it could be thought that ground projects are only self-directed. While some of our ground projects can certainly be only self-directed, this is not the most generous interpretation when thinking about loving relationships. After all, ground projects such as those of being a good son, parent, friend, or lover necessarily involve taking into account the interests of others too. Indeed, I would not be a good son if I only act out of my own interest when I save my mother: I should also consider my mother's interest. Some ground projects, thus, need not be only self-directed; they can be other-directed too.

Nonetheless, the projects view has a pertinent problem. Namely, it is faces the Extension Objection. Let me elaborate. Any account of reasons of love must be able to justify why we are morally permitted, or sometimes even required, to give special treatment to some individuals. Such a story ought to cover various relationships which we generally think are characterized by reasons of love: friendships, romantic relationships, parent-child relationships,

5 Indeed, the project of writing a $\mathrm{PhD}$ thesis or of parenting is quite different from the desire or preference to have Ben and Jerry's ice cream, for example, as much as one likes ice cream and as much as Ben and Jerry's is a delicious ice cream, especially when compared to other ice creams.

6 Susan Wolf (1992), following Williams, argues that we create and express ourselves as individuals partly through our particular commitments, including our commitments to certain people, and that those commitments are then sources of reasons. 
and the relationship between siblings. However, as Keller (2013: 39-41) argues, the projects view is unable to cover those cases in which others do not figure in our ground projects. Consider a realistic relationship between siblings. Imagine you and your brother have very different personalities and as a result you do not play a major role in each other's lives. Nevertheless, you still see each other a few times a year, talk occasionally on the phone, and take a modest but genuine interest in one another. Imagine further that your somewhat estranged brother and a person completely unknown to you are drowning in the Danube. Are you justified in saving your brother instead of a stranger? Most people would say that you are. But, this justification cannot based on the notion of a ground project, for your brother is not a part of any of your ground projects.

Surely, it is possible for an advocate of the projects view to bite the bullet and to admit that the projects view cannot cover all cases. Admitting this theoretical limitation comes at a high price, however, for there are other competing accounts which do not face this challenge. That is, the Extension Objection points out that if the projects view aims to provide a comprehensive justification of our reasons of love, it is problematically incomplete. Moreover, it directs us to look for an explanation elsewhere. Let us now turn to the second attempt to justify reasons of love - the relationship view - which promises to provide a more complete account.

\section{The Relationship View}

The projects view, I argued, cannot be extended to cover all cases in which we think we have reason of love. The extension problem which the projects view faces hints at the second plausible way to pin down reasons of love: it points to the ethical significance of relationships themselves. We value our relationships with others, Samuel Scheffler, the most ardent exponent of the relationship view, holds, not (merely) because they help us to achieve some further goals; rather, we (also) value them for their own sake. Indeed, few would deny this insight. To value relationships non-instrumentally, Scheffler continues to argue, means to consider them as the source of our reasons of love (2010: 100-104). ${ }^{7}$

The relationship view could be also interpreted as claiming that some particular facts about the relationship - past, present, or future - provide us with reasons of love. This is, I believe, what Virginia Held has in mind when she writes that the reason why a child honors her father is not because the child thinks that honoring one's father is generally a good thing, but because the particular father is worth honoring for the reasons that can be elucidated by describing the details of the relationship over the years (2006: 79-80). This also appears to be the reading of the relationship view that Diane Jeske

$7 \quad$ See also: Kolodny (2003). 
(2008) upholds. Although there can be two readings of the relationship view, a compelling objection affects both interpretations.

The relationship view does not face the extension problem. However, it might be argued that the relationship view, on either interpretation, faces the opposite problem. Call this the Overgeneralization Objection. Namely, it could be thought that the claim is that any relationship will do. Thus, even a person who is in an abusive relationship, it could be objected, could have reasons of love towards her abuser if she values that relationship noninstrumentally. However, if you are in an abusive relationship, it is plausible to hold, you do not have reasons of love towards your wrongdoer; quite the opposite, perhaps, you have reasons to give less weight to her well-being than to the well-being of a stranger. Indeed, few people would hold you morally at fault, I suspect, for not giving more weight to the well-being of your abusive mother in comparison to the well-being of a stranger. ${ }^{8}$

This would not be, however, the most charitable reading of the relationship view. A defender of the relationship view, after all, could deny that we have a reason to value abusive relationships. Indeed, "a relationship that is destructive or abusive," as Scheffler casually mentions towards the end of his paper, "lacks the value that makes it a source of reasons to begin with" (2010: 128). The thought is, then, that the relationships which generate reasons of love are those which are valuable in a particular way or which have valuable aspects. Although we might be tempted to ask in virtue of what a relationship possesses or lacks value or valuable aspects regardless of whether someone values that relationship or not, a defender of the relationship view cannot provide us an answer to this query, for a response would require going beyond the relationship itself. This need not be a knock-down argument against the relationship view, however, because one might be content with leaving the view fairly intuitive.

Even if we accept a rather intuitive version of the relationship view, there is a more pertinent problem with the account. Namely, unlike the projects view, the relationship view faces the Focus Objection. Keller presents a phenomenological version of the focus objection in the following way:

A person who characteristically thinks of her relationships when she acts well toward others is not someone you would want as a friend or loved one. A friend who is always thinking of improving your friendship, a colleague whose main concern is with the value of collegiality, a parent who thinks mainly of how important it is to have a

8 Cases of such "partiality gone bad" (in lack of a better term) are not only fairly common in real life but they are also philosophically interesting. If we are morally justified in giving more weight to the well-being of our loved ones, are we also morally justified in giving less weight to the well-being of those whom we hate? As most, if not all, philosophers who consider the phenomenon of partiality are focused on cases of favorable treatment of those whom we love (in some sense), I accept this restriction. 
good relationship with his child all of these characters are annoying to have around, and all of them seem to be missing what really matters in their relationships. In a relationship with such a person, you may feel that he cares less for you than for his relationship with you. He cares less for you yourself than for a role that he wants you to fill (2013: 63).

The key point Keller makes, I take it, is that we want our loved ones to act for our own sake. Indeed, my mother would surely be disappointed if she were to learn that I saved her because I feared that our valuable relationship would no longer exist. She would have hoped that I saved her because she matters to me. A proponent of the relationship view might be tempted to reply that although we might indeed be motivated by a concern for our loved one, it is the loving relationship that produces the reasons why we are justified in acting in such a way. If she were to make this move, however, an advocate of the relationship view would be separating moral justification (the relationship) from moral motivation (the loved one) (Keller 2013: 63-64). Such a move not only makes the relationships view lose its appeal, it is, more strongly, an unacceptable response on the part of a view which is committed to the idea that the justification of reasons of love should be in accordance with our everyday motivation for being partial to our loved ones. ${ }^{9}$

Since the projects view cannot cover all relevant cases and the relationship view lacks a proper focus, what other justification might we offer for reasons of love? The third account found in the literature - the individuals view aims to vindicate reasons of love while avoiding these two problems. The following section, hence, is dedicated to the individuals view.

\section{The Individuals View}

In her best-known academic book, The Sovereignty of Good, Iris Murdoch provides the seed of the third attempt to justify reasons of love: she writes that "love is knowledge of the individual" (1970: 28). Nonetheless, it is Simon Keller (2013) who gives the most elaborate and a highly promising version of the individuals view. The individuals view holds, roughly, that reasons of love "arise from facts about the individuals" (Keller 2013: 79) with whom we share a loving relationship, and not from some relational property.

The basic idea is that persons have certain properties that make them valuable to us. It is that valuable property that gives us reasons of love: they are the appropriate response to the value of individuals. What is that valuable property of individual persons? It cannot be something morally arbitrary, such as beauty, intelligence, or humor. These characteristics may be explanations for liking a person but they cannot be a part of a moral justification of reason of love. The best candidates, then, seem to be morally relevant properties like rationality, autonomy, interests, sentience, or capabilities to flourish.

9 Thanks to an anonymous reviewer for pressing me to clarify parts of this section. 
Immediately, however, the individuals view seems to face the Indeterminacy Objection. After all, it appears that the account lacks the resources to say that we have reasons of love at all: other individuals, besides my loved ones, have a valuable property like rationality, autonomy, sentience, or capabilities. If this is so, then we have little reason to give preference to any particular individual. Keller is keenly aware of this problem; in order to avoid this objection, thus, he offers a more sophisticated story.

In his elaboration of the individuals view, Keller holds that a person's value is tied up to her having "a particular, distinct perspective on the world" (2013: 142) and then draws on Jonathan Dancy's (2004) idea of 'enablers' to explain why we are justified in giving preference to some particular individuals over others. Enablers affect reasons without being reasons per se; that is, enablers are background conditions that explain why something counts as a reason. So, while each person possesses equal value, the fact that I participate in a relationship with my mother puts me in a privileged position to experience, understand, and appreciate her distinctive value as a person. The fact I am in a favorable position to appreciate my mother's value as a person enables her value to provide me with a reason to be partial towards her, just like the fact that you are in a favorable position to appreciate your mother's value as a person provides you with a reason to be partial to your mother. However, since your mother is a stranger to me - I share no relationship with her - I do not have any reason to treat her favorably. Thus, I am morally permitted, if not required, to be partial to my mother and you are morally permitted, if not required, to be partial to your mother on the grounds that participating in a relationship enables their individual value as persons to be known to each of us (Keller 2013: 133-144).

Such a solution to the indeterminacy problem is quite intriguing; yet, Keller concedes that it is ultimately "primitivist" inasmuch as it does not provide any further story as to "why the fact that you share a relationship with someone should enable her self-standing value to generate special reasons for you" (2013: 135. Emphasis in the original.). Despite this deficiency, Keller maintains that his view ought to be preferred for it has significant advantages over the other two competing accounts. Indeed, unlike the relationship view, first, the individuals view has a proper focus: the person whom we love. Second, unlike the projects view, the individuals view is comprehensive enough (because it makes use of relationships) to account for a variety of cases in which we typically hold that reasons of love reign, such as the estranged siblings case which presents a problem for the projects view.

While I think that Keller is on the right track, his individuals view is not an overall superior justification of reasons of love. This is because Keller's solution is vulnerable to some important problems. As I argue in the following section, however, there is a version of the individuals view which does not face these issues. Before that, let us see what the problems for Keller are. 
By applying the notion of enablers to relationships, first, Keller is driven into rejecting an otherwise plausible principle: namely, he denies that "if two entities have the same kinds of value, then any reasons generated by the value of the first entity must also be generated by the value of the second entity" (Keller 2013: 114). Consequently, Keller has two options. On the one hand, he could deny that the value of individuals with whom I do not stand in a valuable loving relationship does not provide me with reasons for action since the relevant enabling condition is not met. This is clearly not an acceptable route to take as it would amount to a rejection of the idea of moral egalitarianism. Thus, Keller opts for the second path: he accepts that reasons of love - the reasons I have to save my mother - are different in kind from what we can call reasons of justice - the reasons I have to save a stranger (Keller 2013: 114). However, it then becomes unclear how relationships transform one kind of a reason into another and what the relevant difference between the two kinds of reasons is supposed to be. Moreover, it is an unnecessary move: a justification of reasons of love need not lead us to open some difficult questions if we make use of another notion.

Second, if we accept that my reason to save my mother is of a different kind than my reason to save a stranger, reasons of love appear to be morally arbitrary. After all, that I am able to form a relationship with my mother, my friends, or my partner is detemined by morally irrelevant features of both our circumstances in life as well as of people's character. Clearly, I did not choose my mother, nor did my mother choose me. Although in some sense we choose our friends and romantic lovers, this choice is also limited by our morally irrelevant circumstances in life, such as where we live, where we work, what our socio-economic status is, and perhaps even what gender/race/ sexual orientation we are, and as well as by amoral properties of persons, such as wit. Indeed, it is difficult to see what morally relevant explanation Keller could offer. As I argue in the following section, however, this issue can be surmounted too if we take a different route.

In accounting for reasons of love, the individuals view is, generally speaking, right to place the focus on individuals. It is also promising because it is comprehensive enough to apply to various cases where reason of love reign. However, Keller's articulation of the individuals view makes reasons of love both mysterious and morally arbitrary. The individuals view can be rendered more plausible if we give up the idea that relationships function as enablers of reasons and uphold the idea that relationships intensify our reasons. Taking this route also hints at a plausible answer as to why it is not morally arbitrary to give preference to those whom we love. The following section is, therefore, dedicated to giving more details about this possible path. 


\section{An Alternative Love Story}

The guiding question of this paper is: what justifies our reasons of love? That is, what moral reasons do we have to give favorable treatment to those people whom we love? So far, I argued that this question is not adequately answered by appealing to neither (i) the value of ground projects, nor (ii) the value of loving relationship themselves, nor (iii) the enabled value of individuals. Nevertheless, the individuals view presents itself as the most promising strategy. The main taks of this section is to present a different version of the individuals view. While I too begin from the value of individuals to justify reasons of love, I argue that relationships have an intensifying role because of their importance for a life worth living. Though such a version of the individuals view is an impartial account, it is better suited to deal with the problems faced by the version of the individuals view examined in the previous section.

\section{The First Step Towards a Solution: The Value of Individuals and Relationships as Intensifiers}

The first step in developing a more satisfactory story about reasons of love is to accept that the value of individuals generates reasons for action. Since each person possesses equal value, we have a reason to treat everyone with equal concern. This is precisely what the moral equality of persons thesis holds. I do not provide an argument for this thesis, as it is widely accepted as an axiom from which contemporary moral and political philosophy must start (Anderson 1999; Dworkin 2000, 2011; Kymlicka 2002; Christiano 2007; and others). ${ }^{10}$ But, how do we go about justifying that we are sometimes permitted, if not required, to treat some particular others favorably?

I believe that Keller's idea of using relationships as Dancy-style enablers is a step in the right direction. However, instead of thinking of valuable loving relationships as enablers, it is better to think of them as 'intensifiers.' (It is interesting to note that Keller mentions intensifiers in a parentheses but does not make any use of this idea.) Intensifiers, as the name suggests, increase the strength of already existing considerations that speak in favor of performing an action (Dancy 2004: 41-42). To appreciate the distinction between reasons, enablers, and intensifiers, consider the following two examples.

Imagine that a famous artist is having, for the first time in your lifetime, an exhibition in your home city. That the show is in your home city coupled with the fact that you can afford the ticket enables you to go to see the exhibition. Suppose, however, that tomorrow is the last day of the exhibition. This is not in itself a reason to attend the exhibition: perhaps you do not like

10 Nevertheless, providing a defense of this claim may indeed turn out to be "one of the most profound problems of moral philosophy" (Christiano 2007: 54). 
art at all or you simply do not like that particular artist. But, if you do like art or you wish to see the work of that particular artist, then the fact that tomorrow is the last day of the exhibition gives more weight to your reason to attend it.

Or consider a different example. You are shopping for a new shirt for work. As you look around your preferred store, you pick up two shirts. Both fit you well and both are of the same quality and price. You have a reason to buy either one of them. However, one of the shirts is in your favorite color black - and the other is a color you don't like - red. The fact that one of the shirts is black tips the scale in favor of buying that shirt and not the other one. Still, the fact that the shirt is black is not a reason on its own to buy it: perhaps the shirt does not fit your body type.

The suggestion is, hence, that while our reasons of love are grounded in the value of individuals, the fact that we stand in a valuable loving relationship with some individuals makes a difference to how strong those reasons are. To return to the Drowning Mother case: the fact that two persons are drowning gives me a reason to save them both, but the fact that I share a loving relationship with one of them - my mother - gives added weight to my reason to save her but does not give any added weight to my reason to save the stranger. The difference between the reason I have towards my mother and the reason I have to the stranger is not one of kind but rather of degree.

It could be objected that relationships do not play the role of intensifiers at all; relationships are, the criticism may go, additional reasons. After all, it is sensible that two reasons in favor of an action also provide us with a stronger case in favor of that action than either of the two reasons taken in isolation. Moreover, we commonly talk about relationships as reasons: this is a point the advocate of the relationship view makes. While it is most likely the case that in ordinary conversations we do not distinguish between reasons, enablers, and intensifiers, this does not mean that there is no distinction to make. A reason could be an additional one if it favors doing something independently of any other reason to do that something. However, standing in a relationship with someone, regardless of how loving it is, is not an independent reason as I argued in the section on the relationship view. Relationships seem to do their normative work only when there are other reasons around. It is, therefore, more plausible to think of relationships as intensifiers rather than as additional reasons.

(Does this mean that I am committed to claiming that someone who cites the black color of shirt as a reason for buying it is wrong? Or that a person is wrong to say that the reason why they are going to an art show is because it is the last day of the exhibition? Not necessarily. After all, when we engage in ordinary conversations with others, we do so with a very different project in mind than when we engage in philosophical analyses. My friends, in all likelihood, do not particularly care, for example, whether I bought my new 
shirt simply because it was black and I happen to like that color or whether the fact that it was black only gave more weight to my reasons for buying a new shirt, which were that I needed one and that this one fit me nicely. Even if I say to my friends that I bought the shirt because it was black, it is implied that I needed one and that this one looked good on me. Saying "It's black." is a shorthand because my friends, like most people, are not really interested in listening to me giving them a precise elaboration: they just want to hear something that is explanatorily relevant.)

This justification is a version of the individuals view as it begins from the value of individuals. It thus has a proper focus. However, it lacks the mysteriousness problem of the individuals view as formulated by Keller inasmuch as it does not claim that the reason I have to save my mother is different in kind from the reason I have to save a stranger. Both these reasons are of the same kind: they stem from the value of individuals. That the only reasons we have to act are grounded in the value of individuals also makes the justification an impartial one. Nevertheless, the fact that we stand in valuable loving relationships with some people but not with others, modifies our reasons by making our reason to attend to a particular someone stronger than our reason to attend to anyone. Given that this version of the individuals view makes use of valuable loving relationships too, it also circumvents the extension problem of the projects view. Incidentally, I also believe that this understanding of the role loving relationships play in making our moral decisions is "truer to the phenomenology of partiality" (Keller 2013: 80).

However, the story remains incomplete; for, why do relationships play this part? Absent an explanation, it remains unclear why reasons of love are not morally arbitrary. This brings us to the second step of a more satisfactory account of reasons of love.

\section{The Second Step Towards a Solution: Relationships and a Meaningful Life}

The second step towards a full story about reasons of love is to account for the relevance of valuable loving relationships. Why might my relationship with my mother give more weight to my reason to save her? This is the point at which, I think, the projects view (or at least what I take the lesson behind it to be) can come to the rescue, though what follows is certainly not the mainstream interpretation of the projects view.

Williams's writing is a delightful fusion of thoughtful and obscure. His idea of ground projects, examined in the previous section, is no exception. There are two ways in which one can interpret the thought that our ground project justify reasons of love. One strand is anchored in a particular view about personal identity: ground projects have their characteristic normative power because of the key role they play in constituting who we are as persons. 
I examined this idea in section 2; I thus leave it aside and focus on the second strand of thought. The second element of Williams's view maintains that ground projects give meaning to our lives. Susan Wolf maintains that the idea of a meaningful life is crucial to Williams's thought. As I understand her, Wolf (2010) holds that a meaningful life, or a life worth living, is a life which consists in the pursuit of objectively valuable goods. The suggestion, then, is that loving relationships are objectively valuable goods; as such, they are one important ingredient of a life worth living. Why do valuable loving relationships figure in living a meaningful life? To answer to this question we need to see what the value of loving relationship consists in.

Loving relationships contribute to a life worth living in various ways. ${ }^{11}$ First, being the kind of creatures that we are, it is plausible to think that we need personalized relationships in which we are valued for who we are and in which we value others for who they are in order to have a sense of belonging. This need is not only deep but it is all-encompassing too: we typically want to have many of our needs met within the context of loving relationships. We commonly prefer to eat, live, travel, learn, and play with people with whom we have, or with whom we would welcome, a loving relationship.

Second, relying on the empirical studies conducted by John T. Cacioppo and his colleagues, Kimberley Brownlee argues that "when we are deprived of adequate social connections ... we tend to break down mentally, emotionally, and physically" (2016: 55). Indeed, as the research Brownlee cities indicates, valuable loving relationships contribute to health and longevity. An actual or perceived lack of loving relationships has been linked to numerous detrimental health outcomes, such as greater likelihood of increased systolic blood pressure and cardiovascular diseases, depression and anxiety, personality disorders, impaired cognitive performance and decline of cognitive abilities over time, and increased risk of Alzheimer's disease and dementia (Cacioppo and Patrick 2008. Cited in Brownlee 2016).

Third, relationships arguably play a crucial role in the development of autonomy; alternatively, they might constitute autonomy itself. These are two claims of those who propose a relational approach to understanding individual autonomy. In any case, relational conceptions of autonomy, which stem mostly from feminist insights, stress the ubiquitous role that relationships play in a person's self-conception and which must be taken into account when outlining the conditions for individual autonomy (Mackenzie and Stoljar 2000).

Finally, it is plausible to hold that loving relationships are a necessary for achieving some other valuable goods, such as self-confidence and trust in others. Indeed, our friends, family members, and lovers provide us with necessary encouragement and advice about our life plans and about our

11 What follows is not intended to be a comprehensive explanation. 
abilities to carry those plans out. (Think of the encouragement and advice you received from your parents, for example, when choosing what to study. Or think of the support you received from your partner or friends when you ventured into a risky business.) It is also within loving relationships that we develop a sense of trust in others. Having a sense of trust is not only crucial for survival (especially for those who depend on others for care: children, the elderly, and the physically and mentally impaired) (Kittay 2011) but it is also necessary in order to cooperate with others (Friedrich and Southwood 2011). The sense of trust we develop through our interpersonal relationships is germane, furthermore, for living in a political community: we need to trust fellow citizens, institutions, and politicians to uphold the social contract in order for society to function and to function well (Govier 1997, O'Neill 2002).

The argument, then, is as follows. Loving relationships contribute to a life worth living. If loving relationships are a vital ingredient for a life worth living, then they affect our reasons for action. The best explanation of how exactly loving relationships affect our reasons for action is that they act as intensifiers. That loving relationships play this role does not make reasons of love morally arbitrary because living a worthy life is morally relevant. Indeed, I can hardly think of anything that matters more to us than having a life worth living. And this matters equally to each and every one of us.

\section{Conclusion}

The main goal of this paper was to provide a compelling justification of reasons of love. To that end, I examined three prominent accounts in the literature - the projects view, the relationship view, and one version of the individuals view. These three ways of justifying reasons of love are ultimately unsuccessful, or so I argued. The projects view, first, lacks comprehensiveness; second, the relationship view does not have the proper focus; finally, the individuals view, at least in Keller's articulation, makes reasons of love not only vague but also a matter of moral chance. Nevertheless, since there is much support for the individuals view, I then presented a version of the individuals view that circumvents the problems which cause trouble for Keller's account. I suggested that while the justification of reasons of love is firmly grounded in the equal value of individual persons, the reason I have towards my loved ones has more weight because loving relationships play the role of intensifiers of reasons. Such a version of the individuals view avoids making reasons of love mysterious - for, there is only a difference in degree but not in kind - and morally arbitrary - for, loving relationships are an important part of a life worth living. If you are convinced by such a multilayered story, you can then proceed with a clear moral conscience to throw the life jacker to your drowning mother should you ever find yourself in such a situation. Hopefully, you won't. 
I promised to deliver one other thing at the beginning of the paper. Due to brevity of space and the intricacy of the issue, I can only canvass it briefly. Namely, let us accept that we are justified in giving preference to our loved ones over strangers. It surely cannot be the case that we are always morally permitted to give preference to our loved ones: benefiting our loved ones has its limits. What is that limit? This is a difficult question, for there are plenty of situations in which we might find ourselves that would fall under a gray area. Is there a principled way to distinguish between cases in which it is morally permissible to be partial to our loved ones and cases in which it is morally impermissible to be partial to our loved ones?

I think that a sensible answer to this question lies in whether the benefits we give to our loved ones are ours to give or not. If I am a public servant (national or international), for example, I am charged with considering the benefit of everyone equally (baring deontological considerations). Therefore, it would be morally impermissible to be partial to my loved ones simply because they are my loved ones: the goods I command are not mine to give away. It is the violation of this requirement, I think, which fuels the idea that practices such as nepotism and cronyism (to take one example) are morally wrong. In juxtaposition, in cases in which the goods I am allocating are mine (be they material or non-material), reasons of love are permitted, perhaps even required (Hooker 2010). To be sure, this is merely a tentative and a highly unsophisticated response. Luckily, my aim in this paper was not to settle this issue but merely to provide an account that gives a plausible story behind reasons of love.

\section{References}

Anderson, Elizabeth (1999). "What Is the Point of Equality?” Ethics 109 (2): 287-337.

Brownlee, Kimberley (2016). "Ethical Dilemmas of Sociability." Utilitas 28 (1): 54-72.

Cacioppo, John T. and Patrick, William (2008). Loneliness: Human Nature and the Need for Social Connection. New York: W. W. Norton \& Company.

Christiano, Thomas (2006). "A Foundation for Egalitarianism." In: Nils Holtug and Kasper Lippert-Rasmussen (eds.). Egalitarianism: New Essays on the Nature and Value of Equality. Oxford: Clarendon Press.

Dancy, Jonathan (2004). Ethics Without Principles. Oxford: Oxford University Press.

Dworkin, Ronald (1977). Taking Rights Seriously. Cambridge, MA: Harvard University Press.

Dworkin, Ronald (2000). Sovereign Virtue: The Theory and Practice of Equality. Cambridge, MA: Harvard University Press. 
Dworkin, Ronald (2011). Justice for Hedgehogs. Cambridge, MA: The Belknap Press of Harvard University Press.

Friedrich, Daniel, and Southwood, Nicholas (2011). "Promises and Trust." In: Hanoch Sheinman (ed.). Promises and Agreements: Philosophical Essays. Oxford: Oxford University Press.

Govier, Trudy (1997). Social Trust and Human Communities. Montreal: McGill-Queen's University Press.

Held, Virginia (2006). The Ethics of Care: Personal, Political, and Global. New York: Oxford University Press.

Hooker, Brad (2010). “When Is Impartiality Morally Appropriate?” In: Brian Feltham and John Cottingham (eds.). Partiality and Impartiality: Morality, Special Relationships, and the Wider World. Oxford: Oxford University Press.

Jeske, Diane (2008). Rationality and Moral Theory: How Intimacy Generates Reasons. New York: Routledge.

Keller, Simon (2013). Partiality. Princeton: Princeton University Press.

Kittay, Eva F. (2011). “The Ethics of Care, Dependence, and Disability." Ratio Juris 24 (1): 49-58.

Kolodny, Niko (2003). "Love as Valuing a Relationship." The Philosophical Review 112 (2): 135-189.

Kymlicka, Will (2002). Contemporary Political Philosophy: An Introduction, 2nd edition. Oxford: Oxford University Press.

Mackenzie, Catriona and Stoljar, Natalie (2000). "Introduction: Autonomy Refigured." In: Catriona Mackenzie and Natalie Stoljar. Relational Autonomy: Feminist Perspectives on Autonomy, Agency, and the Social Self. New York: Oxford University Press.

Murdoch, Iris (1970). The Sovereignty of Good. London: Routledge.

O'Neill, Onora (2002). A Question of Trust: The BBC Reith Lectures. Cambridge: Cambridge University Press.

Scheffler, Samuel (2006). "Projects, Relationships, and Reasons." In: Michael Smith et al. (eds.). Reason And Value: Themes from the Moral Philosophy of Joseph Raz. Oxford: Oxford University Press: 247-269.

Scheffler, Samuel (2010). "Morality and Reasonable Partiality." In: Brian Feltham and John Cottingham (eds.). Partiality and Impartiality: Morality, Special Relationships, and the Wider World. Oxford: Oxford University Press: 98-130.

Williams, Bernard (1981). Moral Luck: Philosophical Papers 1973-1980. Cambridge: Cambridge University Press. 
Wolf, Susan (1992). "Morality and Partiality." Philosophical Perspectives 6: 243-259.

Wolf, Susan (2010). Meaning in Life and Why It Matters. (With Commentary by John Koethe, Robert M. Adams, Nomy Arpaly, and Jonathan Haidt.) Princeton: Princeton University Press. 